\title{
GeoEtrim 2020 executed version: an academic software for geospatial image evaluation
}

\author{
Yunus Emre Elkar ${ }^{1}$ (D), Huseyin Topan ${ }^{2 *}$ (I) \\ ${ }^{1}$ Tapu Kadastro Mesleki ve Teknik Anadolu Lisesi, Çankaya, Ankara, Turkey. \\ ${ }^{2}$ Zonguldak Bulent Ecevit University, Campus of Farabi, Faculty of Engineering, Department of Geomatics Engineering, Zonguldak, Turkey.
}

\begin{abstract}
GeoEtrim (Geospatial Evaluation and Training of Images) is a set of academic software packages to evaluate optical images geospatially. Although GeoEtrim was developed in the MATLAB environment in the past, it was decided to be compiled in another programming language $(\mathrm{C \# )}$ in order to overcome the challenges like importing/reading very big sized image files, collecting Ground Control Point (GCP) and Independent Check Point (ICP) in an easy way and running the orientation models, etc. Creating projects, importing image(s), enhancing the image contrast, collecting GCP\&ICP and running sensor independent orientation models through subpackage GeoTransform are the major opportunities of the current version. In addition, GeoTransform itself enables blunder and parameter validation tests. GeoEtrim can also be used free-of-charge for academic purposes; therefore, its user community increases rapidly. This paper focus on both theoretical background and graphical user interface of GeoEtrim 2020 executed version.
\end{abstract}

Keywords: GeoEtrim, Coordinate transformation, Sensor orientation, Graphical user interface, Geospatial information

\section{GeoEtrim 2020 sürümü: Konumsal görüntü değerlendirme için akademik bir yazılım}

Öz: GeoEtrim (Geospatial Evaluation and Training of Images), optik görüntüleri konumsal olarak değerlendirmek için geliştirilen akademik yazılım paketler bütünüdür. GeoEtrim geçmişte MATLAB ortamında geliştirilmiş olsa da, çok büyük boyutlu görüntü dosyalarının içe aktarılması/okunması, yer kontrol noktalarının ve bağımsız denetim noktalarının kolay bir şekilde toplanması ve çeşitli hesaplamaların yapılmasındaki zorlukların üstesinden gelinmesi için başka bir programlama dilinde (C \#) derlenmesine karar verilmiştir. Proje oluşturmak, görüntüleri içe aktarmak, görüntünün zltlığını geliş̧tirmek, yer kontrol noktaları ve bağımsız denetim noktalarını toplamak, GeoTransform alt paketi aracılığlyla algılayıcıdan bağımsız yöneltme yöntemlerini çalıştırmak mevcut sürümün sunduğu başlıca özelliklerdir. Ek olarak, uyuşumsuz ölçü testi ve parametre anlamlılık testleri de özellik olarak eklenmiştir. GeoEtrim akademik çalışmalar için ücretsiz olarak kullanılabilir ve böylelikle kullanıcı topluluğu her geçen gün artabilir. Bu makalede GeoEtrim 2020'nin hem kuramsal yapısı hem de grafik kullanıcı arayüzü tanıtılmaktadır.

Anahtar Sözcükler: GeoEtrim, Koordinat dönüşümü, Algılayıcı yöneltmesi, Grafik kullanıcı arayüzü, Konumsal bilgi 


\section{Introduction}

Thanks to the investment on the geospatial services, geospatial information has become one of the most significant components in daily life of an ordinary citizen. According to the report by AlphaBeta (2017), the size of geospatial services has reached $\sim 400$ billion United States Dollar (USD) market share. Image-based data acquisition such as close-range, aerial or spaceborne optical, microwave, thermal or laser acquisition systems has an important role in the generation of geospatial information (Chen et al., 2016). The world has witnessed 181 remote sensing satellites (except meteorological ones) with 17.4 billion USD budget in recent years and the additional budget is expected to be 8.5 billion USD by 2026 (Euroconsult, 2017). As pointed by United Nations, the geospatial services based on remote sensing support the globally sustainable development goals of humanity (Paganini et al., 2018).

The improving geospatial services depend on the developments of various components such as customer's needs, data acquisition, hardware, software and algorithms etc. Since this paper is devoted to software, we will only focus on this component. A great number of academic or commercial software programs have been developed up to now. The commercial software could be preferred in an application-based task; nevertheless, the question is which software should be chosen in a research or an educational activity. The major reason of this challenge is that the theoretical background and algorithms are not comprehensively known by user, and the user is restricted to choose many options most of which is generally assumed default. One might think that this user-tendency appears only in the countries following the science-makers. On the contrary, this is also a trouble in developed ones, as pointed out by Dowman (2010) as “...There's a danger that people, institutions and organizations are using data without understanding how they were acquired, or explaining wrongly... ...And I tend to think that, at least from a UK perspective, more young people are going to university, but not choosing the difficult studies involving mathematics and science". Following this motivation, GeoEtrim is being developed to fully control all workflow starting the characteristics of an image and ending the final product/result. This motivation presents a didactic behavior with the help of various kinds of scientific publications and user guide (GeoEtrim, 2020).

Numerous academic software has been developed for the purpose of generation/research of geospatial information from image-based data for the last decades. Some of them are developed and freely distributed by the national/international organizations, for instance, Sentinel Application Platform (SNAP) by European Space Agency (ESA) (2020), gvSIG, QGIS and GRASS GIS by Open Source Geospatial Foundation (OSGeo, 2020), MicMac by National Institut Géographique National and l'École de la Géomatique (IGN \& ENSG, 2020), Orfeo Toolbox by the Orfeo ToolBox Project Steering Committee (Grizonnet et al., 2017), CloudCompare (2020), MeshLab (2020), Barista (CRCSI, 2020), while some were handled by the individuals or teams, such as COSI-Corr (Ayoub, Leprince, \& Keene, 2009), Bundle block adjustment Leibniz University Hannover (BLUH) by Jacobsen (2008), E-foto (Mota et al., 2012), Phox (Luhmann, 2016), inteGRAted PHOtogrammetric Suite (GRAPHOS) (Gonzalez-Aguilera et al., 2018), VisualSFM (Wu, 2020), Bundler (Snavely, 2020), Theia (2020), COLMAP (2020), Clustering Views for Multi-view Stereo (CMVS) (Furukawa, 2020), Patch-based Multiview Stereo Software (PMVS) (Furukawa \& Ponce, 2018), A Multi-View Reconstruction Environment (MVE) (Fuhrmann, Langguth, \& Goesele, 2014), sv3DVision (Aguilera \& Lahoz, 2006), Photogrammetry Workbench (González-Aguilera et al., 2012), Python Photogrammetry Toolbox (Moulon \& Bezzi, 2011), Open Drone Map (Waechter, Moehrle, \& Goesele, 2014), DGAP (Stallmann, 2020) etc. Besides those open source and/or freeware solutions, some academic software are commercially distributed, such as SATellite image Precision Processing (SAT-PP), PHOENIX, CLOse RAnge MAtching (CLORAMA), Least Squares 3D Surface Matching (LS3D) and Bundle Adjustment with Additional Parameters (BAAP) by 4DiXplorer (2018), A Satellite Image Processing Platform for High Resolution Forest Assessment (FORSAT, 2018), and Photogrammetric Surface Reconstruction from Imagery (SURE) by Rothermel and Wenzel (2020) etc. It is beneficial to bear 
in mind for the users that many of commercial software include tools developed for academic purposes.

Similar to the ones mentioned before, GeoEtrim has the motivation of present academic software for scientific and educational contribution to the international community. Its chronological developments are summarized below.

\section{General Overview of GeoEtrim}

The origin of GeoEtrim was based on programming of some sensor independent orientation models, polynomial (limited with $5^{\text {th }}$ degree), affine projective and Direct Linear Transformation (DLT), developed in MATLAB environment (Topan, 2004; Topan, Buyuksalih, \& Kocak, 2005). Later, the affine projective approaches considering IKONOS, OrbView-3, and QuickBird image geometry, and a new quality checking approach called figure condition were implemented within GeoFigcon tool by Topan and Kutoglu (2009). This approach was extended by (Topan, 2013; Topan, Taskanat, \& Cam, 2013; Topan, Oruc, Taskanat, \& Cam, 2014) using sensor dependent Rational Function Model (RFM), and it was preferred by Moghaddam, Mokhtarzade, Naeini, and Amiri-Simkooei (2018). Some other sensor independent models such as similarity, projective and sensor independent RFM were also coded into this tool, and GeoFigcon was renamed as GeoTransform in 2018. With that last version, the outlier detection and parameter validation tests have become available, and the orthoimage generation is still being developed (Cam, 2018).

GeoEtrim does not consist of only the sensor independent orientation models. For instance, GeoSpot is the most complex tool running sensor dependent orientation model specialized for SPOT 5 stereo images (Topan, 2009). This doctorate project was expanded by adding the parameter validation test and self/cross correlation among the interior/exterior orientation parameters (Topan \& Maktav, 2014). Based on the principle of GeoSpot, Geo3o1 was developed for the new generation sensor orientation models for Pléiades 1A/1B and SPOT 6/7 triplet images (GeoEtrim, 2020). Terlemezoglu and Topan (2020) overcame the ill-posed orientation problem via eigenvalue-based novel approaches.

Although the innovative approaches were programmed in MATLAB environment, the user-friendly and all-in-one solutions were required for the end-users' easy-to-use. Some of the limitations were the difficulties in collection of Ground Control Point (GCP) and Independent Check Point (ICP) in MATLAB environment and the requirement of auxiliary software for this purpose. The other limitation was that although the theoretical background was given in the lessons of bachelor, master or doctorate programs, the users needed setting-up at least a MATLAB runtime to run the executed version. The feedback from the users forced us to give a decision of executed version, which is presented in this paper.

\section{C\# Version of GeoEtrim}

Since this paper explains the new version of GeoEtrim written in C\#, the libraries, the graphical user interface (GUI) of GeoEtrim and theoretical background of GeoTransform have been mentioned.

\subsection{Programming Language and Libraries}

The mentioned version of GeoEtrim in this paper has been coded in C\#, which was started to develop by Anders Hejlsberg through $\mathrm{C}$ and $\mathrm{C}++$ in Microsoft Corporation (Hejlsberg, Wiltamuth, \& Golde, 2003). Users have an opportunity to code with C\# more easily than older versions and is more object-oriented without losing performance. Since C\# has not directly integrated with the machine language, .Net Framework and Mono platform are required for Windows and Linux operating systems, respectively. This framework presents some opportunities making the coding easier, such as namespace and Base Class Library (BCL), which is mostly preferred for basic mathematical functions and variables during the coding of 
GeoEtrim. The version of .Net Framework version is 4.6.

GeoEtrim uses the libraries such as Geospatial Data Abstraction Library (GDAL), Emgu Computer Vision (EmguCV) and ALGLIB for image reading/processing and algebraic requirements, respectively. As an OSGeo project, GDAL could read, process, analyse, translate and write raster and vector data, and C\#, Python, Java, and Perl versions are available. Many software packages, which process remote sensing images use a wide range of opportunities presented in GDAL. GeoEtrim also uses its image reading function supporting 155 image formats. GeoEtrim requires EmguCV library for image processing. This library is derived from the OpenCV library, which is available in C and C++ (Shi, 2013). Image zooming, showing image histogram, contrast enhancement and histogram equalization, GCP/ICP marking on image and the matrix operations were performed by using this library. ALGLIB is a library to cross-platform numerical analysis and data processing supporting $\mathrm{C}++, \mathrm{C} \#$ and Delphi languages. This library was only needed for t-distribution value in GeoTransform. It should be noticed that the language for GUI, variables and coding are in English to ensure international cooperation and usage.

\subsection{Workflow and Principal Properties}

The workflow of GeoEtrim was illustrated in Figure 1, consisting of three main components, i.e. main user interface, GCP/ICP collection interface and GeoTransform.

The main user interface consists of top menus such as File for project management, tools for importing image and contrast enhancement, and GCP/ICP collection, and Modules having sub-programs (only when GeoTransform is active), and Help (Figure 2a). Some shortcut menus such as open/save projects, import/delete image, active image name, zooming and dragging tools, contrast enhancement and GCP/ICP collection interface are available under the top menu. The user can see the name of project and images, and can open original bands and their histograms of each image by the image information interface. Additionally, GCP/ICPs could be shown or hidden by clicking the related button below in each band. This option supports an easy understanding of a multispectral image.

One of the difficulties in visual interpretation of remotely sensed images is working with low contrast datasets. This challenge must be overcome for easy collection of GCP/ICPs. Thanks to the EmguCV, the user is able to enhance the image contrast with manual or automatic options (Figure 2b). The user can define a scale factor between 0.125 and 4.5 for multiplying the grey scale in the manual mode with the option of histogram equalization.

GeoEtrim saves the project file in structure of eXtensible Markup Language (XML). XML is formed by intermingled character data and mark-up allowing a hierarchical structure for each image (writing image name, directory, number of row and column etc.) and the information of GCP/ICPs per image (Identification (ID), type (control or check), coordinates (image and object) and their standard deviations). This hierarchical structure allows easy managing and saving the project file having multiple images and their GCP/ICPs. Figure 3 illustrates a project file in XML format.

The user can collect GCP/ICPs of the working image by a user-friendly interface (Figure 4a). When clicking on the image in the main user interface, the image coordinates (row and column in pixel unit) are automatically transferred into the relevant boxes, and the point is shown in the Distribution of Points window. Both control or check points are collected in this same interface by changing the point type. The user can import the GCP/ICPs by the loading an existing file, and if the auto locate function is activated, the marked point in the list is automatically located in the centre of image window at the main user interface. This option allows seeing the point on the original image easily at the main user interface. Since this interface might cover a large portion of the user's working screen, there is an option to reduce its size allowing the essential parts, which remain while others are ignored (Figure 4 b). Figure 4c shows the GCP/ICP exporting options. The user can select and change 
the sequence of point ID and type, image and ground coordinate axes and standard deviations. Both GCPs and ICPs or only one type could be exported. The number of decimal place for coordinates and standard deviations, and the separator for decimal place, columns and column titles could be arranged by this interface. All these options give the user the flexibility of setting in an exported file.

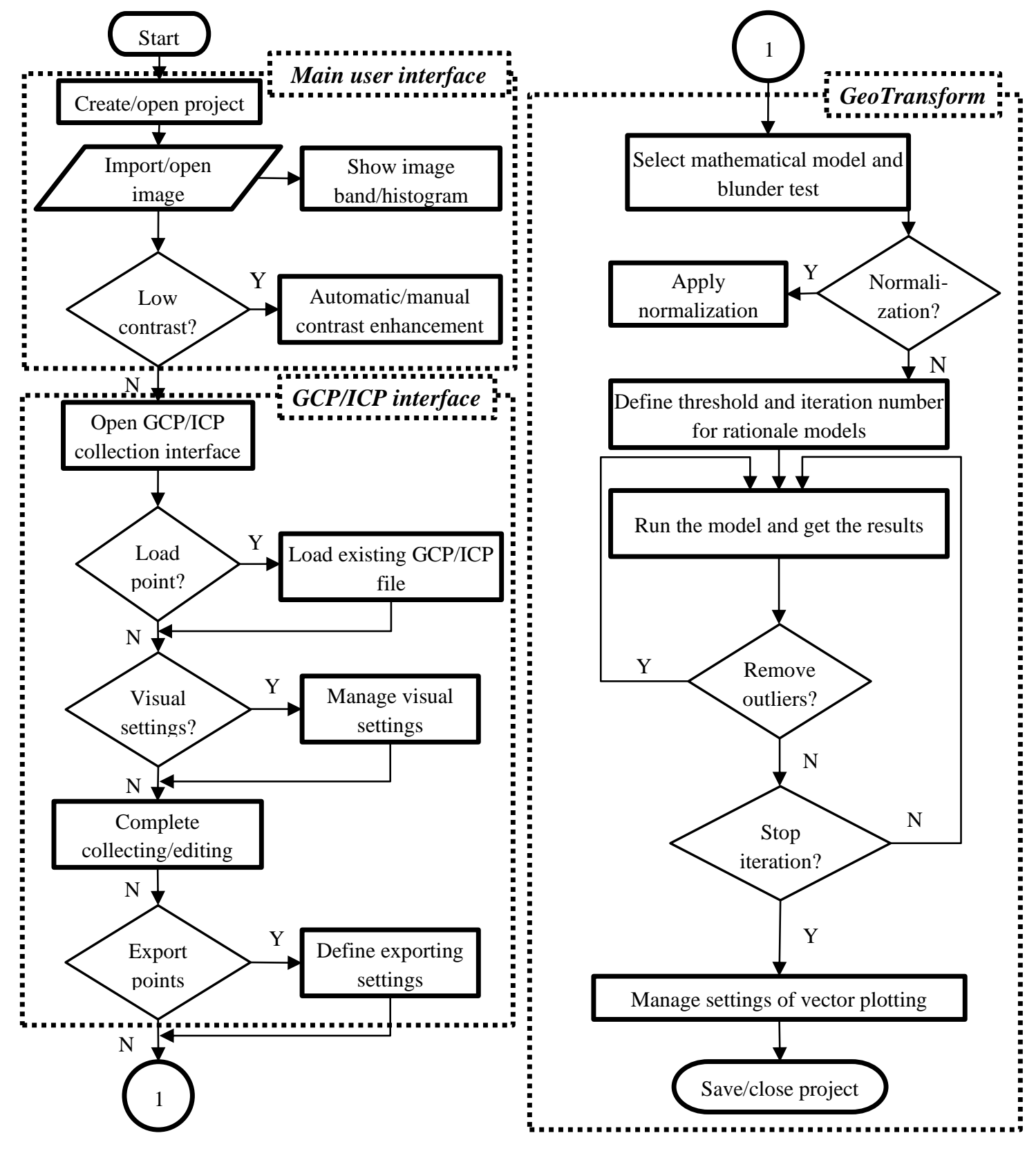

Figure 1: Workflow of GeoEtrim

Another issue, which is served is a wide range of colour and size settings for GCP/ICPs, point list and GeoTransform (Figure 5). These settings allow comfortable usage of these interfaces and also support better presentation of GeoTransform reports. For instance, the size, colour, ID or type of a GCP/ICP marker can be changed upon the user's request. When the user wishes to return the default settings, the system allows it. 


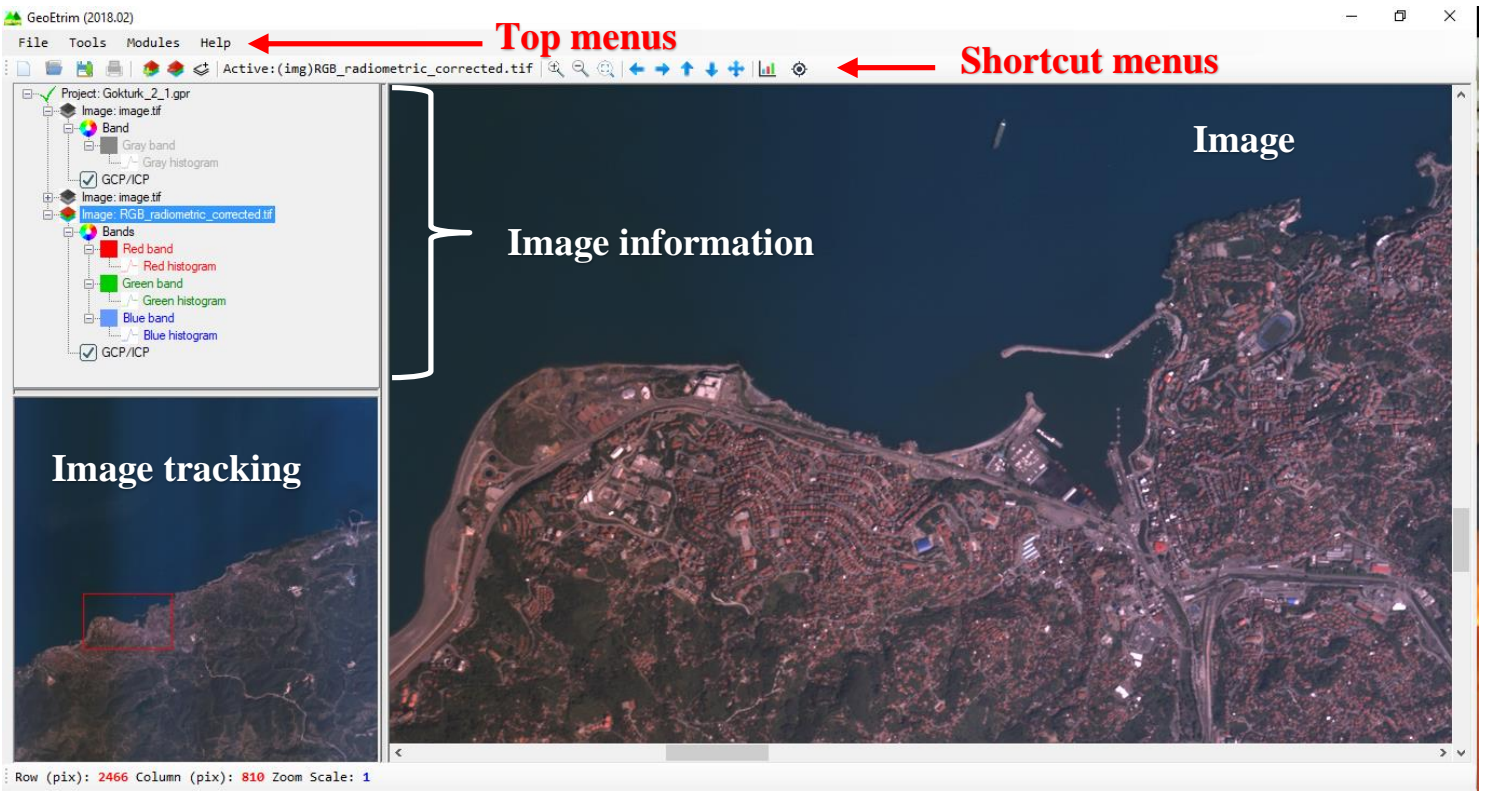

(a)
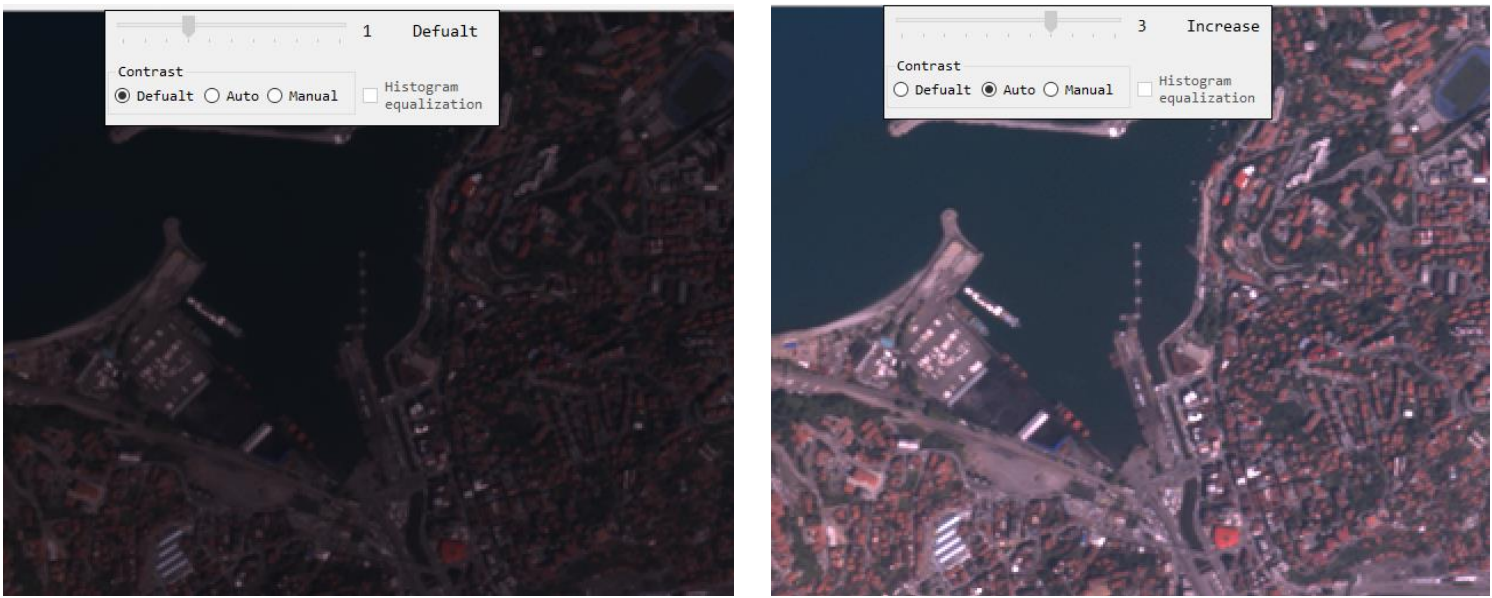

(b)

Figure 2:Main user interface and a sample of contrast enhancement via Göktürk-2 multispectral image. (a) Main user interface of GeoEtrim. (b) Sample for contrast enhancement

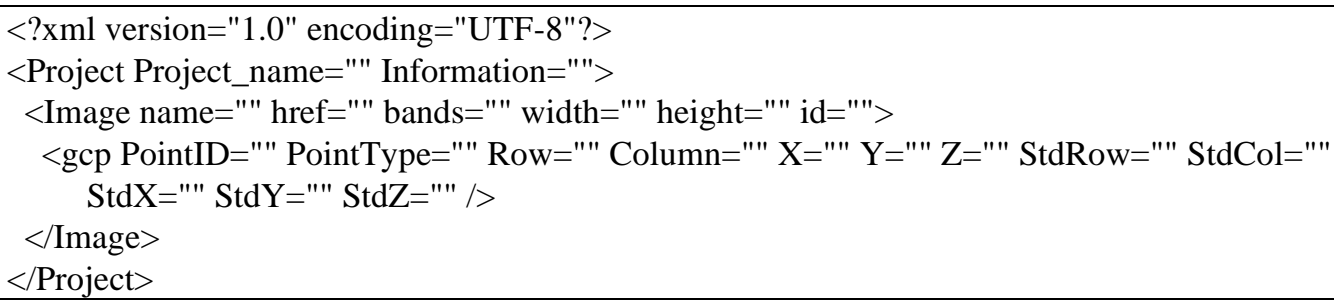

Figure 3:XML structure of project file

\section{GeoTransform}

As mentioned before, GeoEtrim executed version has GeoTransform tool for sensor independent orientation although its' MATLAB version has GeoSpot and Geo3o1 tools. The user has the options of selecting the orientation (transformation) model, the threshold value and maximum iteration number for rationale methods (such as projective, DLT and RFM), method of blunder test, normalization option for avoiding the ill-conditioning and the visual setting of vector plotting. At first, the theoretical background of sensor independent orientation, adjustment and blunder detecting test will be introduced, then its user interface will be presented. 


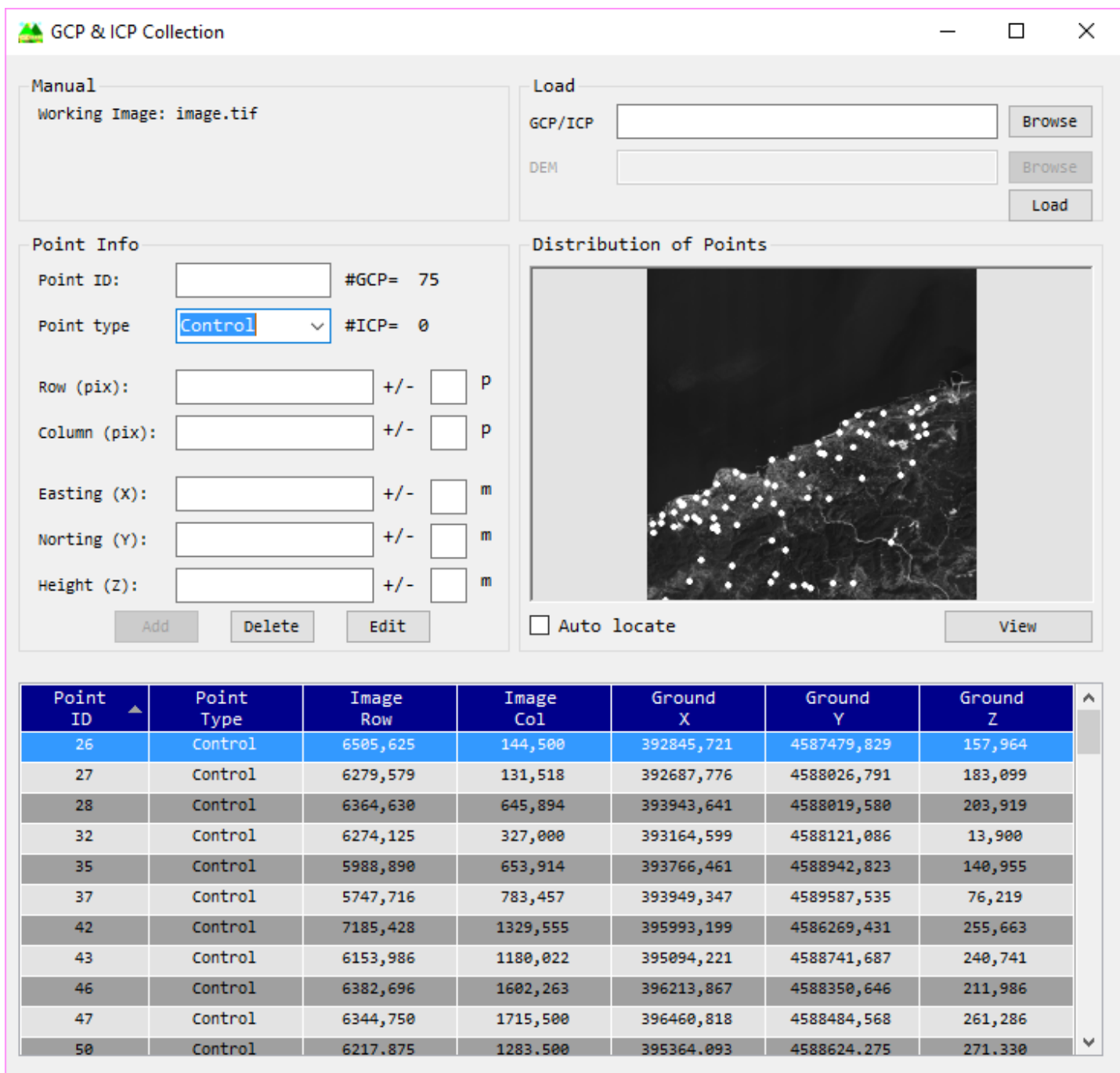

(a)

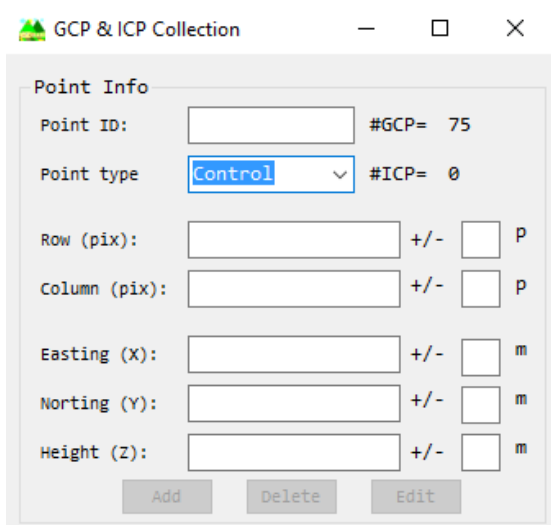

(b)

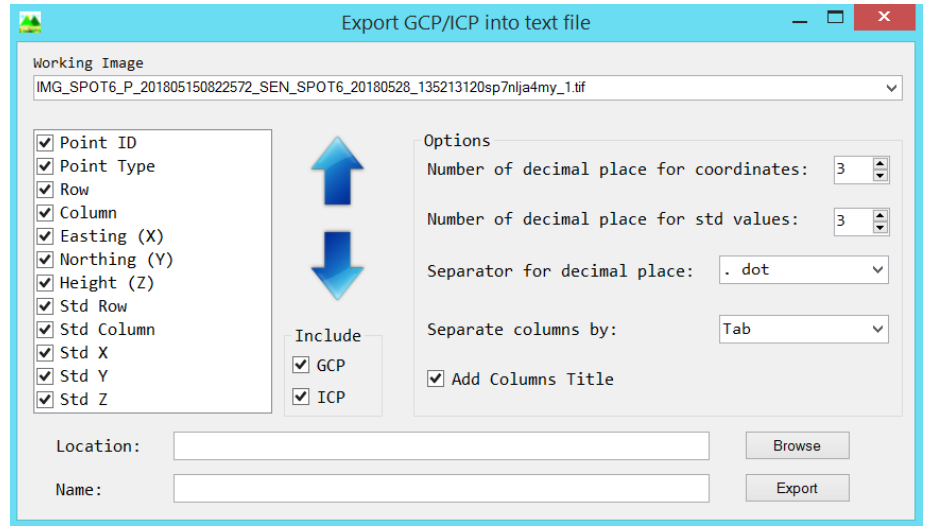

(c)

Figure 4: GCP/ICP collection and setting interfaces. (a) GCP/ICP collection interface (wide format). (b) GCP/ICP collection interface (minimized format). (c) GCP/ICP exporting interface 


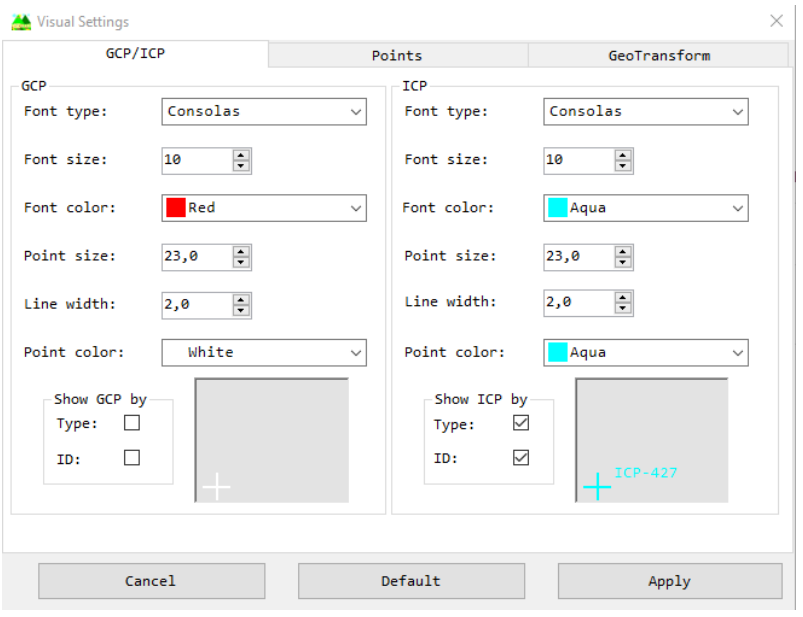

Figure 5:Visual settings for GCP/ICPs, points and GeoTransform

\subsection{Sensor Orientation Models}

Generation of geospatial information needs establishing the relationship between image (terrestrial, aerial or remotely sensed) and object (ground, map) coordinate systems. In this way, each pixel of image could have their corresponding object coordinates. This process is generally called as georeferencing, geocoding or geolocating. The goal of sensor (image) orientation is to establish coordinate transformation between image and object coordinate systems. The mathematical models of sensor orientation are varied in sensor dependent and independent. The sensor dependent models strive to present the real geometric relationship between image and object coordinate systems with the help of auxiliary coordinate systems. For instance, the models for linear array optical systems are established considering the coordinate transformation in the sequence of image, linear array, camera, body (platform), orbital, inertial and ground coordinate systems. This means such kind of orientation model needs all parameters reflecting the geometric relationship between them. On the other hand, the sensor independent models directly establish this transformation between image and ground coordinate systems ignoring the real geometric characteristics.

The sensor independent orientation models of GeoTransform are similarity (Helmert), 2 Dimensional (2D) polynomial, affine projective, projective, DLT and sensor independent (terrain dependent) RFM. Its MATLAB version has also the sensor dependent (terrain independent) RFM, and various matrix inversion and regularization methods to solve ill-posed problem (Aytekin, Topan, Elkar, Kisi, \& Erisik, 2019). The simplest model is similarity transformation assuming ground space in 2D. This model has two shifts in two dimensions, one scale and one orientation angle. Its formulation is

$\left[\begin{array}{l}r_{i} \\ c_{i}\end{array}\right]=\left[\begin{array}{l}X_{0} \\ Y_{0}\end{array}\right]+s\left[\begin{array}{cc}\cos \propto & -\sin \propto \\ \sin \propto & \cos \propto\end{array}\right]\left[\begin{array}{c}X_{i} \\ Y_{i}\end{array}\right]=\left[\begin{array}{c}a_{00}+a_{10} X_{i}-a_{01} Y_{i} \\ b_{00}+a_{01} X_{i}+a_{10} Y_{i}\end{array}\right]$

where $r$ and $c$ are row and column coordinates, respectively, $X_{0}$ and $Y_{0}$ are shift through $\mathrm{X}$ and $\mathrm{Y}$ axes, $s$ is scale and $\propto$ denotes the orientation angle, $X$ and $Y$ mean the ground coordinates, and $i=1, \ldots, n, n=2 \times$ number of GCPs. Since a shape is forced in this model, the expected accuracy is generally low. The second model is polynomial transformation formulated as

$r_{i}=\sum_{j=0}^{m} \sum_{k=0}^{m} a_{j k} X_{i}^{j} Y_{i}^{k}, c_{i}=\sum_{j=0}^{m} \sum_{k=0}^{m} b_{j k} X_{i}^{j} Y_{i}^{k}$

where $a$ and $b$ are the polynomial coefficients. The $1^{\text {st }}$ order polynomial is called affine transformation, and each coefficient is related to the geometric distortions of images (Zoej, 1997). The third model is affine projection. This model considers the 
third dimension (i.e. height) of object space, as following

$r_{i}=a_{000}+a_{100} X_{i}+a_{010} Y_{i}+a_{001} Z_{i}$

$c_{i}=b_{000}+b_{100} X_{i}+b_{010} Y_{i}+b_{001} Z_{i}$

This model was extended for fitting geometry of QuickBird OrthoReady and IKONOS Geo products by Jacobsen (2003) as following

$r_{i}=a_{000}+a_{100} X_{i}+a_{010} Y_{i}+a_{001} Z_{i}+a_{101} X_{i} Z_{i}+a_{011} Y_{i} Z_{i}$

$c_{i}=b_{000}+b_{100} X_{i}+b_{010} Y_{i}+b_{001} Z_{i}+b_{101} X_{i} Z_{i}+b_{011} Y_{i} Z_{i}$

and for OrbView-3 images (Buyuksalih, Akcin, \& Jacobsen, 2006)

$r_{i}=a_{000}+a_{100} X_{i}+a_{010} Y_{i}+a_{001} Z_{i}+a_{101} X_{i} Z_{i}+a_{011} Y_{i} Z_{i}+a_{200} X_{i}^{2}$

$c_{i}=b_{000}+b_{100} X_{i}+b_{010} Y_{i}+b_{001} Z_{i}+b_{101} X_{i} Z_{i}+b_{011} Y_{i} Z_{i}+b_{110} X_{i} Y_{i}$

The fourth model is projective transformation, which establishes the central projection characteristics of images. Nevertheless, only the planimetric ground coordinates are taken into account. It is formulated as

$r_{i}=\frac{a_{00}+a_{10} X_{i}+a_{01} Y_{i}}{1+c_{10} X_{i}+c_{01} Y_{i}}, \quad c_{i}=\frac{b_{00}+b_{10} X_{i}+b_{01} Y_{i}}{1+c_{10} X_{i}+c_{01} Y_{i}}$

The $3^{\text {rd }}$ dimension ignored in projective transformation is considered in DLT, which is derived by Abdel-Aziz and Karara (1971) from the collinearity equations well known in photogrammetry. This is formulated as

$f_{1}=a_{000}+a_{100} X_{i}+a_{010} Y_{i}+a_{001} Z_{i}$

$f_{2}=b_{000}+b_{100} X_{i}+b_{010} Y_{i}+b_{001} Z_{i}$

$f_{3}=1+c_{100} X_{i}+c_{010} Y_{i}+c_{001} Z_{i}$

$r_{i}=\frac{f_{1}}{f_{3}}, c_{i}=\frac{f_{2}}{f_{3}}$

So DLT does not need the interior and exterior orientation parameters in contrast to the collinearity equations. Moreover, the interior and exterior orientation parameters could be estimated from the DLT coefficients (Seedahmed \& Schenk, 2001).

The last model is the sensor independent RFM. Its generic formulation, which is valid for both sensor dependent and independent versions, is

$f=\sum_{g=0}^{m_{g}} \sum_{j=0}^{m_{j}} \sum_{k=0}^{m_{k}} P_{g j k} X_{i}^{g} Y_{i}^{j} Z_{i}^{k}$

$r_{n_{i}}=\frac{f_{a}}{f_{b}}, \quad c_{n_{i}}=\frac{f_{c}}{f_{d}}$ 


\subsection{Adjustment}

Adjustment process is an essential step to estimate both corrected (adjusted, compensated) image coordinates and also the orientation elements with the most probable values. The approximate values of coefficients in the sensor independent models are zero at the beginning. Since the number of observations is more than the number of unknowns (coefficients), the degree of freedom is higher than zero (i.e. $f>0, f=n-u$ ). This allows us to run adjustment via Least Squares Estimation (LSE). Let us show the mathematical model

$(r, c)_{i}=\mathrm{F}\left\{P_{j},(X, Y, Z)_{i}\right\}$

where $\mathrm{F}$ defines the orientation model and $P$ is the coefficient. The ground coordinates are considered free of error. The adjustment with observation equations among various types of adjustment models fits the models presented above mentioned. So, the adjusted observations $(r, c)$ are estimated as following when the weight matrix is identity matrix (I) (Koch, 1999)

$\overline{\boldsymbol{\ell}}=\boldsymbol{\ell}+\mathbf{v}=\boldsymbol{\ell}_{0}+\mathbf{A d P}$

$\mathbf{d P}=\left(\mathbf{A}^{\mathbf{T}} \mathbf{A}\right)^{-1} \mathbf{A}^{\mathbf{T}}\left(\boldsymbol{\ell}-\boldsymbol{\ell}_{0}\right)$

$\mathbf{Q}_{\mathrm{dpdp}}=\left(\mathbf{A}^{\mathrm{T}} \mathbf{A}\right)^{-1}$

$\mathbf{Q}_{\ell \ell}=\mathbf{A} \mathbf{Q}_{\mathrm{dpdp}} \mathbf{A}^{\mathrm{T}}$

$\mathbf{Q}_{\mathrm{vv}}=\mathbf{I}-\mathbf{Q}_{\ell \ell}$

$\overline{\mathbf{P}}=\mathbf{P}_{0}+\mathbf{d P}$

$\mathbf{v}=\ell_{0}-\boldsymbol{\ell}+\mathbf{A d P}$

$m_{r}= \pm \sqrt{\frac{\mathbf{v}_{r}^{T} \mathbf{v}_{r}}{f}}, m_{c}= \pm \sqrt{\frac{\mathbf{v}_{c}^{T} \mathbf{v}_{c}}{f}}$

$m_{0}= \pm \sqrt{\frac{\mathbf{v}^{\mathbf{T}}}{f}}$

where $\boldsymbol{\ell}$ is the observation, $\mathbf{v}$ means the residuals, $\boldsymbol{\ell}_{0}$ shows the approximate values, $\mathbf{P}_{0}$ is the approximate values of unknowns, $\mathbf{d P}$ means the unknowns, $\mathbf{Q}_{\mathrm{dpdp}}$ is the cofactor matrix of unknowns, $\mathbf{Q}_{\ell \ell}$ is the cofactor matrix of the adjusted observations, $\mathbf{Q}_{\mathrm{vv}}$ is the cofactor matrix of residuals, $f$ is the degrees of freedom, $\mathbf{A}$ denotes the Jacobian matrix constituted by coefficients, and the posteriori accuracy $\left(m_{0}\right)$ is expected $m_{0} \leq \pm 1$ pixel (Leprince, Barbot, Ayoub, \& Avouac, 2007). Additionally, $\left[\mathbf{v}_{r}\right]=0,\left[\mathbf{v}_{c}\right]=0$, and $[\mathbf{v v}]=\min$ are expected since LSE is preferred. The rationale functions such as projective, DLT and RFM need the iterative solution. $\mathbf{P}_{0}=0$ and $\boldsymbol{\ell}_{0}=0$ at the first iteration, and the adjusted coefficients $(\overline{\mathbf{P}})$ and image coordinates $(\overline{\boldsymbol{\ell}})$ are replaced in the iteration up to the limit for iteration (iteration number or the difference between $m_{0}$ of consecutive iterations) as illustrated in Figure 1.

Since the ill-conditioned Jacobian matrix might possibly arise, all coordinates are normalized into \pm 1 for stable matrix inversion. The normalization is applied for row coordinates, for instance, as following: 
$r_{n}=\frac{2 r-r_{\max }-r_{\min }}{r_{\max }-r_{\min }}$

and remains follow the similar formulation. This option is preferred by the user (Figure 1).

The outliers could be estimated to ignore some GCPs, which reduce the posterior accuracy. GeoTransform presents two options, normal (Baarda test) and $t$ distribution, as following (Baarda, 1968; Koch, 1999)

Normal distribution: $T_{n_{i}}=\frac{\left|v_{i}\right|}{\sigma_{o} \sqrt{Q_{v v_{i, i}}}}$

$t$ distribution: $T_{i}=\frac{\left|v_{i}\right|}{m_{0 \mathrm{i}} \sqrt{Q_{v v_{i i}}}}$, where $m_{0 \mathrm{i}}=\sqrt{\frac{[\mathbf{v v}]-\frac{v_{i}^{2}}{{\mathrm{Q} v v_{i i}}}}{f-1}}$

where $\alpha=0.05$ and $\sigma_{o}$ is defined by the user. If $T_{i}>t_{f-1,1-\alpha / 2}$ subsequently, the $\mathrm{i}^{\text {th }}$ GCP is assumed outlier.

The orientation model has coefficients some of which can be negligible. Such coefficients could be statistically estimated by validation test as following

$m_{d P_{i}}= \pm m_{0} \sqrt{Q_{d P d P_{i i}}}$

$T_{i}=\frac{\left|P_{i}\right|}{m_{d P_{i}}}$

where $m_{d P}$ is the posterior accuracy of coefficient. If $T_{i}>t_{f, 1-\alpha / 2,}, \alpha=0.05$, the coefficient is assumed as significant and is reported by GeoTransform.

\subsection{User Interface}

This section consists of the user interface of GeoTransform (Figure 6). The left part of GeoTransform allows to select working image, the mathematical model and model ID $\left(1^{\text {st }}-5^{\text {th }}\right.$ degrees of polynomial model, three types of affine projection or $1 \mathrm{st}-$ 3rd of RFM), the type of blunder detection test (normal or t distribution), a priori $\sigma_{o}$ if the normal distribution is selected, threshold to terminate the iterative models (projective, DLT and RFM) and the maximum iteration number. If a rationale mathematical model is run, the maximum iteration number is reached and the difference between $m_{0}$ of the last two iterations are displayed in a message box. The quality of adjustment is shown in the relevant section including $m_{\mathrm{r}}, m_{\mathbf{c}}, m_{0},\left[\mathbf{v}_{\mathbf{r}}\right],\left[\mathbf{v}_{\mathbf{c}}\right]$, $[\mathbf{v v}]$, and the number of points considered in the adjustment, degree of freedom and the invalid parameters in a message box.

The right side is designed for the graphical representation of residuals. Analyzing the direction of residuals is important as much as their magnitude. They are expected to be non-systematic in a proper orientation. The user could open the image behind the vectors, and the residuals are presented in a rose-diagram to visualize their dominated directions. There are some options to magnify the scale factor, and to change the size of GCP/ICP dot and width of vector for better visualization. 


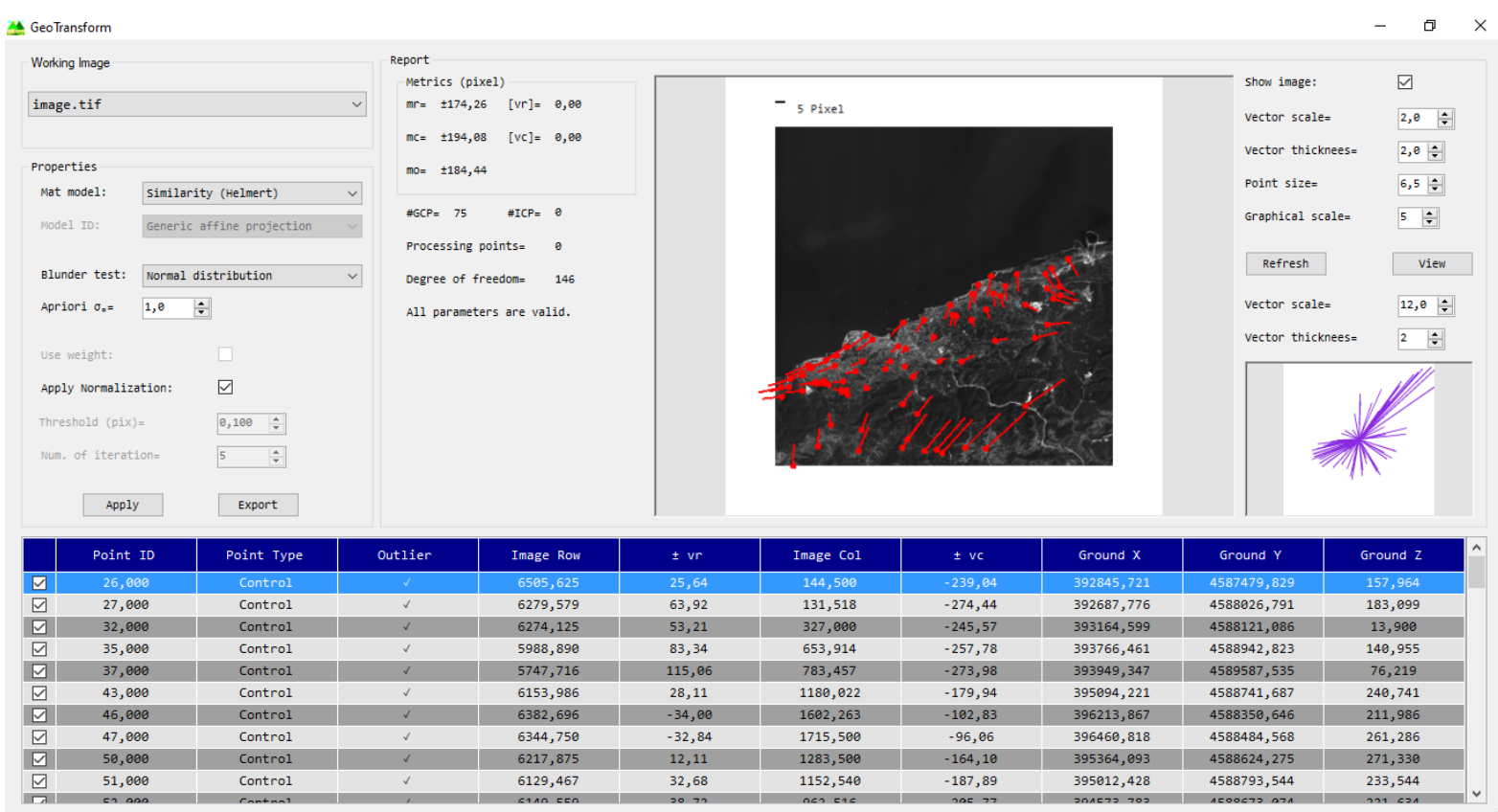

Figure 6:User interface of GeoTransform. Samples is related to the Göktürk-2 panchromatic image

\subsection{Sample Application}

Results of a sample application are presented for Göktürk-2 panchromatic images ( $2.5 \mathrm{~m}$ ground sampling distance) dated 27.05.2014 (Table 1). 75 GCPs were collected from Pléiades 1A panchromatic images. Those results were confirmed the GeoTransform's MATLAB version derived by Cam (2018). Figure 7 presents the vector graphics of residuals of similarity, DLT and $1^{\circ}$ RFM methods.

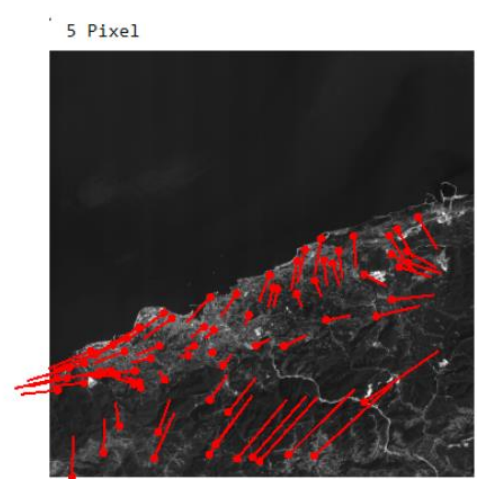

Similarity.

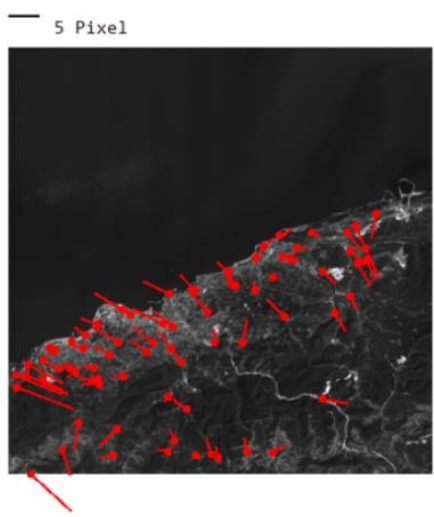

DLT

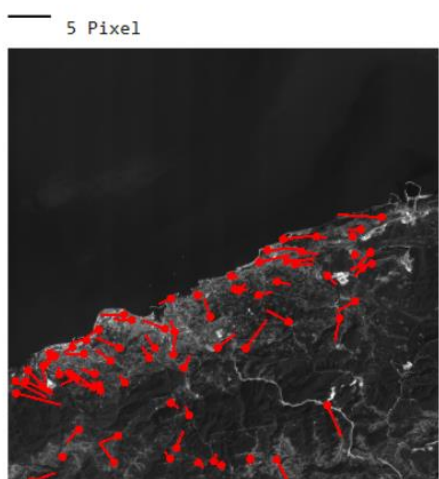

$1^{\circ} \mathrm{RFM}$

Figure 7:Sample of vector graphic of residuals

\section{Community}

GeoEtrim aims to be established by both international user and developer community. It is distributed free-of-charge for research and educational activities through its account via http://github.com/geoetrim. A website (http://www.geoetrim.org) also allows the detailed information about tools, team, publications, presentations and contact. GeoEtrim is actively used in the applications of the lessons at bachelor, master and doctorate programs in Zonguldak Bulent Ecevit University, Department of Geomatics Engineering, and is being developed by substantial feedback. The team is growing with the new members, the master and doctorate students advised by the second author, and the students and their advisors from the Department of Computer Engineering (Karabuk University), and also the contributors from related communities. 
Table 1: 2D georeferencing accuracy ( \pm pixel)

\begin{tabular}{cccc}
\hline Method & $\boldsymbol{m}_{\boldsymbol{r}}$ & $\boldsymbol{m}_{\boldsymbol{c}}$ & $\boldsymbol{m}_{\mathbf{0}}$ \\
\hline Similarity & 174.26 & 194.08 & 184.44 \\
\hline Affine (1॰ polynomial) & \multirow{2}{*}{1.87} & 5.27 & \multirow{2}{*}{3.95} \\
\hline $1^{\circ}$ polynomial (Affine) & 0.91 & 4.09 & 2.96 \\
\hline $2^{\circ}$ polynomial & 0.89 & 4.05 & 2.94 \\
\hline $3^{\circ}$ polynomial & 0.79 & 3.81 & 2.75 \\
\hline $4^{\circ}$ polynomial & 0.75 & 3.68 & 2.65 \\
\hline $5^{\circ}$ polynomial & 1.85 & \multirow{2}{*}{4.00} & 3.11 \\
\hline Affine projection & 0.91 & 2.66 & 1.99 \\
\hline Affine projection (Generic) & 1.75 & 3.95 & 3.06 \\
\hline Affine projection (for IKONOS \& QuickBird geometry) & 2.43 & 4.60 & 3.68 \\
\hline Projective & 2.42 & 2.99 & 2.73 \\
\hline DLT & 1.35 & 2.05 & 1.74 \\
\hline $1^{\circ}$ RFM (sensor independent) & 0.71 & 0.69 & 0.70 \\
\hline $2^{\circ}$ RFM (sensor independent) & 0.47 & 0.38 & 0.43 \\
\hline
\end{tabular}

\section{Conclusion and Further Studies}

This paper presents the new version of GeoEtrim, which is freely available for the academic usage. Although full version consists of sensor dependent and independent orientation models, the version in this paper runs only the sensor independent models. The main motivation of developing such kind of version is to suggest user-friendly software for geospatial image evaluation overcoming the limitations of the MATLAB platform. Therefore, a user can create the project by importing many images, and collecting/importing/exporting the GCP/ICPs, and running the sensor independent orientation models by getting the numerical and graphical results. The theoretical background and details are presented through the software web site.

Although this first executed version has reached a proper structure, it will definitely need further developments in the future. For instance, GeoTransform could be improved by adding sensor dependent RFM for mono and stereo images, and its' imageto-ground version should be taken into account. In spite of the fact that GeoTransform's MATLAB version has the orthoimage generation, the executed version still does not have that capability. Performing the first version of Geo3o1 tool was completed, and its first publication via Pléiades 1A stereo panchromatic images will be soon. This tool is also available for SPOT $6 \& 7$ and Göktürk-1 images. C\# version of GeoEtrim has been stopped since the advisory board of GeoEtrim has decided to continue the developing of GeoEtrim in C++ via Qt environment with GitHub platform to be fully open access project.

\section{Acknowledgements}

The authors would like to thank Murat ORUC for the contribution as a professional user, to Mr. Ali CAM for sharing the MATLAB codes for GeoTransform, to Asst. Prof. Mursel Ozan INCETAS for the contribution as a computer scientist, and also to the Turkish Air Force for the providing Göktürk-2 image.

\section{Author Contribution}

Yunus Emre Elkar: Conception, Design, Analysis and interpretation, Writing. Huseyin Topan: Conception, Design, Literature review, Data collection, Supervision, Writing, Review of article. 


\section{Declaration of Competing Interests}

The authors declare that they have no known relevant competing financial or non-financial interests that could have appeared to influence the work reported in this paper.

\section{References}

Abdel-Aziz, Y. I., \& Karara, M. (1971). Direct linear transformation from comparator coordinates into object space coordinates in closerange photogrammetry. American Society of Photogrammetry: Symposium on Close-Range Photogrammetry, 1-18.

Aguilera, D. G., \& Lahoz, J. G. (2006). sv3DVision: didactical photogrammetric software for single image-based modeling. International Archives of Photogrammetry, Remote Sensing and Spatial Information Sciences, 36(6), 171-179.

AlphaBeta (2017). The Economic Impact of Geospatial Services: How Consumers, Businesses and Society Benefit from Location-Based Information. https://storage.googleapis.com/valueoftheweb/pdfs/GeoSpatial\%2520FA_Pages-compressed\%2520\%25282\%2529.pdf (Accessed: 12 August 2018)

Ayoub, F., Leprince, S., \& Keene, L. (2009). User's guide to COSI-CORR co-registration of optically sensed images and correlation. California Institute of Technology: Pasadena, CA, USA, 38.

Aytekin, G., Topan, H., Elkar, Y. E., Kisi, M., \& Erisik, O. (2019). 2D Orientation Accuracy of Göktürk-1 Panchromatic Imagery. 2019 9th International Conference on Recent Advances in Space Technologies (RAST), 821-826.

Baarda, W. (1968). A Testing Procedure for Use in Geodetic Networks. Publication on Geodesy, 2(5), 97

Buyuksalih, G., Akcin, H., \& Jacobsen, K. (2006). Geometry of OrbView-3 Images. ISPRS Workshop on Topographic Mapping From Space (with Special Emphasis on Small Satellites).

Cam, A. (2018). Algılayıcıdan Bağımsız Dönüşüm Yöntemleri İle Üretilen Ortogörüntülerin Konum Doğruluğunun Belirlenmesi (Master Thesis). Zonguldak Bulent Ecevit University, Graduate Scholl of Natural and Applied Sciences, Zonguldak, Turkey (in Turkish).

Chen, J., Dowman, I., Li, S., Li, Z., Madden, M., Mills, J., Paparoditis, N., Rottensteiner, F., Sester, M., Toth, C., Trinder, J., \& Heipke, C. (2016). Information from imagery: ISPRS scientific vision and research agenda. ISPRS Journal of Photogrammetry and Remote Sensing, 115, 3-21.

CloudCompare (2020). CloudCompare: 3D point cloud and mesh processing software. https://www.cloudcompare.org/ (Accessed: 27 August 2018).

COLMAP (2020). https://demuc.de/colmap/ (Accessed: 27 August 2018).

CRCSI (2020). http://www.crcsi.com.au/impact/barista/ (Accessed: 27 August 2018).

Dowman, I. (2010). Need to Reach Out to Other Sciences. (Durk Haarsma, Publishing Director, GIM International), https://www.giminternational.com/content/article/need-to-reach-out-to-other-sciences (Accessed: 30 August 2018).

Euroconsult (2017). Satellite-based Earth Observation Market: Strong Growth and Fierce Competition. https://www.giminternational.com/content/news/satellite-based-earth-observation-market-strong-growth-and-fierce-competition (Accessed: 30 August 2018)

European Space Agency (ESA) (2020). Sentinel Application Platform (SNAP). http://step.esa.int/main/toolboxes/snap/ (Accessed: 30 August 2018)

FORSAT (2018). A Satellite Image Processing Platform for High Resolution Forest Assessment. http://forsat.eu (Accessed: 30 December 2018).

Fuhrmann, S., Langguth, F., \& Goesele, M. (2014). MVE-A Multi-View Reconstruction Environment. EUROGRAPHICS Workshops on Graphics and Cultural Heritage.

Furukawa, Y., \& Ponce, J. (2018). Patch-based Multi-view Stereo Software (PMVS). https://www.di.ens.fr/pmvs/ (Accessed: 30 December 2018).

Furukawa, Y. (2020). Clustering Views for Multi-view Stereo (CMVS). https://www.di.ens.fr/cmvs (Accessed: 27 August 2020).

GeoEtrim (2020). GeoEtrim: Geospatial Evaluation and Training of Images. www.geoetrim.org (Accessed: 27 August 2020).

González-Aguilera, D., Guerrero, D., Hernández López, D., Rodriguez-Gonzálvez, P., Pierrot, M., \& Fernández-Hernández, J. (2012). PW, 
Photogrammetry Workbench. CATCON Silver Award, ISPRS WG VI/2. Proceedings of the 22nd ISPRS Congress.

Gonzalez-Aguilera, D., López-Fernández, L., Rodriguez-Gonzalvez, P., Hernandez-Lopez, D., Guerrero, D., Remondino, F., Menna, F., Nocerino, E., Toschi, I., Ballabeni, A., \& Gaiani, M. (2018). GRAPHOS-open-source software for photogrammetric applications. The Photogrammetric Record, 33(161), 11-29.

Grizonnet, M., Michel, J., Poughon, V., Inglada, J., Savinaud, M., \& Cresson, R. (2017). Orfeo ToolBox: open source processing of remote sensing images. Open Geospatial Data, Software and Standards, 2(1), 1-8.

Hejlsberg, A., Wiltamuth, S., \& Golde, P. (2003). C\# language specification. Addison-Wesley Longman Publishing Co., Inc. Institut Géographique National (IGN), \& l'École de la Géomatique (ENSG). (2020). MicMac. https://micmac.ensg.eu/index.php/Accueil (Accessed: 27 August 2020).

Jacobsen, K. (2003). Geometric potential of IKONOS-and QuickBird-images. Photogrammetric Weeks '03, 101-110.

Jacobsen, K. (2008). BLUH bundle block adjustment. Program User Manual, https://www.ipi.uni-hannover.de/fileadmin/institut/pdf/ BLUHinfo.pdf (Accessed: 27 August 2020).

Koch, K.-R. (1999). Parameter estimation and hypothesis testing in linear models. Springer Science \& Business Media.

Leprince, S., Barbot, S., Ayoub, F., \& Avouac, J. P. (2007). Automatic and precise orthorectification, coregistration, and subpixel correlation of satellite images, application to ground deformation measurements. IEEE Transactions on Geoscience and Remote Sensing, 45(6), 1529-1558.

Luhmann, T. (2016). Learning photogrammetry with interactive software tool PhoX. The International Archives of Photogrammetry, Remote Sensing and Spatial Information Sciences, 41, 39.

MeshLab (2020). MeshLab: the open source system for processing and editing 3D triangular meshes. http://www.meshlab.net/ (Accessed: 27 August 2020).

Moghaddam, S. H. A., Mokhtarzade, M., Naeini, A. A., \& Amiri-Simkooei, A. (2018). A statistical variable selection solution for RFM ill-posedness and overparameterization problems. IEEE Transactions on Geoscience and Remote sensing, 56(7), 3990-4001.

Mota, G. L. A., Ribeiro, J. A., Bernardo Filho, O., Silveira, M. T., de Aguiar, R. A., da Silva Badolato, I., da Costa, S. L., \& Reolon, P. F. (2012). The e-foto project and the research to implement a GNU/GPL open source educational digital photogrammetric workstation. Geospatial free and open source software in the 21 st century, 89-106. Springer: Berlin, Heidelberg.

Moulon, P., \& Bezzi, A. (2011). Python photogrammetry toolbox: a free solution for three-dimensional documentation. ArcheoFoss, 1-12. Open Source Geospatial Foundation (OSGeo). (2020). OSGeo Projects. https://www.osgeo.org/projects (Accessed: 30 August 2020).

Paganini, M., Petiteville, I., Ward, S., Dyke, G., Steventon, M., Harry, J., \& Kerblat, F. (2018). Satellite earth observations in support of the sustainable development goals. The CEOS Earth Observation Handbook.

Rothermel, M., \& Wenzel, K. (2020). SURE (Photogrammetric Surface Reconstruction from Imagery). http://www.ifp.uni-stuttgart.de /publications/software/sure/index.en.html (Accessed: 30 August 2020).

Seedahmed, G., \& Schenk, T. (2001). Comparative Study of Two Approaches For Deriving The Camera parameters From Direct Linear Transformation. Annual Conference of ASPRS.

Shi, S. (2013). Emgu CV Essentials. Packt Publishing Ltd.

Snavely, N. (2020). Bundler: Structure from Motion (SfM) for Unordered Image Collections. http://www.cs.cornell.edu/ snavely/bundler/ (Acessed: 30 August 2020).

Stallmann, D. (2020). DGAP (Bundle Adjustment). http://www.ifp.uni-stuttgart.de/publications/software/openbundle/index.en.html (Accessed: 30 August 2020).

Terlemezoglu, B., \& Topan, H. (2020). Eigenvalue-Based Approaches for Solving an Ill-Posed Problem Arising in Sensor Orientation. IEEE Transactions on Geoscience and Remote Sensing, 58(3), 1920-1930.

Theia (2020). Theia Vision Library. http://www.theia-sfm.org/ (Accessed: 30 August 2020).

Topan, H. (2004). Yörünge Düzeltmeli IRS-1C/1D Pankromatik Mono Görüntüsünün Geometrik Doğruluk ve Bilgi İçeriği Açısından Incelenmesi (Master Thesis). Zonguldak Karaelmas University, Graduate Scholl of Natural and Applied Sciences, Zonguldak, Turkey (in Turkish).

Topan, H., Buyuksalih, G., \& Kocak, G. (2005) IRS-1C Düzey 1B Görüntüsünün Geometrik Analizinin Sensör Yöneltme Modelleriyle ve Değişik Referans Verileriyle İrdelenmesi. UCTEA Chamber of Survey and Cadastre Engineers, 10. Turkey Scientific and Techical Conference, Ankara, Turkey. 
Topan, H. (2009). Geometric Analysis of High Resolution Space Images Using Parametric Approaches Considering Satellite Orbital Parameters (PhD Thesis). Istanbul Technical University, Graduate Scholl of Natural and Applied Sciences, Istanbul, Turkey.

Topan, H., \& Kutoglu, H. S. (2009). Georeferencing accuracy assessment of high-resolution satellite images using figure condition method. IEEE Transactions on Geoscience and Remote Sensing, 47(4), 1256-1261.

Topan, H. (2013). First Experience with Figure Condition Analysis Aided Bias Compensated Rational Function Model for Georeferencing of High Resolution Satellite Images. Journal of the Indian Society of Remote Sensing, 41(4), 807-818.

Topan, H., Taskanat, T., \& Cam, A. (2013). Georeferencing accuracy assessment of Pléiades 1A images using rational function model. International Archives of the Photogrammetry, Remote Sensing and Spatial Information Sciences, XL-7/W2.

Topan, H., \& Maktav, D. (2014). Efficiency of orientation parameters on georeferencing accuracy of SPOT-5 HRG level-1A stereoimages. IEEE Transactions on Geoscience and Remote Sensing, 52(6), 3683-3694.

Topan, H., Oruc, M., Taskanat, T., \& Cam, A. (2014). Combined efficiency of RPC and DEM accuracy on georeferencing accuracy of orthoimage: Case study with Pléiades panchromatic mono image. IEEE Geoscience and Remote Sensing Letters, 11(6), 1148-1152.

Waechter, M., Moehrle, N., \& Goesele, M. (2014). Let there be color! Large-scale texturing of 3D reconstructions. European conference on computer vision, 836-850. Springer, Cham.

Wu, C. (2020). VisualSFM: A Visual Structure from Motion System. http://ccwu.me/vsfm/doc.html (Accessed: 30 August 2020).

Zoej, M. J. V. (1997). Photogrammetric Evaluation of Space Linear Array Imagery for Medium Scale Topographic Mapping (PhD Thesis). University of Glasgow, Faculty of Science, Glasgow, Scotland. 